\title{
TACKLING THE CHALLENGES IN MULTICULTURAL TEAMS: CHALLENGES CONFRONTED BY MANAGERS AND THE SOLUTIONS THEY DELIVER
}

\author{
DOI: 10.17261/Pressacademia.2018.881 \\ PAP- V.7-2018(34)-p.204-208
}

\author{
Husniye Ors ${ }^{1}$, Nusret Sogancilar ${ }^{2}$ \\ ${ }^{1}$ Gazi University, Emniyet Mahallesi Muammer Bostancı Cad. No:4 Besevler, Ankara, Turkey. \\ ohusniye@gmail.com, ORCID: 0000-0002-8319-3340 \\ ${ }^{2}$ Gazi University, Emniyet Mahallesi Muammer Bostancı Cad. No:4 Besevler, Ankara, Turkey. \\ nsrtsgnclr@gmail.com, ORCID: 0000-0002-9729-5372
}

\section{To cite this document}

Ors, H., Sogancilar, N. (2018). Tackling the challenges in multicultural teams: challenges confronted by managers and the solutions they deliver. PressAcademia Procedia (PAP), V.7, p.204-208.

Permemant link to this document: http://doi.org/10.17261/Pressacademia.2018.881

Copyright: Published by PressAcademia and limited licenced re-use rights only.

\begin{abstract}
Purpose- This study aims to explore the challenges confronted by executive managers while managing multicultural teams, and the solutions they deliver to cope with these matters. Comprehending these challenges from the standpoint of managers is what it is aimed to accomplish.

Methodology- Criterion sampling method, which is a kind of purposive sampling method, was employed in the study. The data for the study was collected through 14 in-depth interviews directed to executive managers of MNCs operating in Turkey. The questions that generated our data consisted of open-ended questions. The statements of managers were analyzed by content analysis and sorted into conceptually corresponding categories. These categories and solutions based upon manager's experiences were presented accordingly. Findings- Implications indicate that ineffective communication and misunderstandings, different working styles and expectations of group members, and intolerance and lack of knowledge related to diversity are the most frequent challenges confronted by managers. On the other hand, in order to cope with these challenges, managers offer to embrace diversity while encouraging group members to acknowledge it, become approachable and eager to learn more, and last but not least it was offered to communicate in the simplest form. Conclusion- To sum up briefly, successful managers are expected to possess the competency to adapt different management styles and they are also expected to be flexible enough to switch from one to another.
\end{abstract}

Keywords: Multicultural teams, management, cross-cultural management, international business, multinational companies. JEL Codes: F23, M12, M16

\section{INTRODUCTION}

Having multicultural teams in today's globalized business world is quite widespread for companies. The reason behind this phenomenon is considered to be the increasing mobility of people and labor on a global scale. Within this context, multicultural work groups have become prevalent and rapidly changing work environment has set novel challenges both for managers and for employees. Therefore, the role of managers as to effectively leading multicultural teams as well as understanding and handling the challenges arising for this reason is pretty significant (Matveev and Milter 2004).

Simply put, it is considered that multinational companies (MNCs) prefer directly investing in foreign markets for certain reasons including market-seeking (desire to find new buyers), resource-seeking (desire to access to cheaper inputs), strategic asset-seeking (desire to build distribution networks and acquire cutting-edge technologies) and efficiency-seeking (Dunning, 2002). In addition, mergers and acquisitions performed between foreign and domestic companies are considered to influence the number of foreign employees working for the company and consequently the number of multicultural teams in international organizations. Studies conducted to investigate MNCs exhibit that one of the serious issues faced by these companies is the management of cross-cultural differences since culture profoundly influences the attitudes of managers, relations in the company, technology transfer, and many other activities (Helvacioğlu and Özutku, 2010). Within this context, it may be regarded that major problems arise in work environments where people from diverse cultural backgrounds are working together.

Previous studies conducted in this realm, mainly focuses on either proper leadership styles that are required to adopt to manage culturally diverse teams or the issues confronted by team members and how they handle these problems including language differences, 
misunderstandings and miscommunication (Mäkilouko, 2004; Behfar et al., 2006; Ramthun and Matkin, 2012; Aritz and Walker, 2014; Lisak and Erez, 2015).

In this study, instead of concentrating on the differences of individual team members and their cultural backgrounds, it has been aimed to address the challenges faced by executive managers while managing multicultural teams as well as the solutions delivered by them. In other words, our goal is to develop an understanding of the challenges faced by managers and the way they handle these challenges. This study is going to concentrate on managers who work for MNCs operating in Turkey since they are more likely to work with people from diverse cultures and confront challenges stemming from these differences that are common in multicultural teams. Comprehending these challenges from the standpoint of managers is what we aim to accomplish.

\section{LITARATURE REVIEW}

\subsection{What is a Multicultural Team?}

Human beings have been experiencing collaboration and cooperation to safeguard the continuity of their existence ever since they existed. Cooperation and collaboration, in this sense, may be regarded as worthwhile and helpful not only for survival but also for efficiency and satisfaction. Emergence and creation of teams can be attributed to this notion (Halverson and Tirmizi, 2008).

Globalization and recent developments in technology have profoundly influenced societies, businesses and the work environment. This is because increasing mobility of labor and entrepreneurs along with capital movements, spread of information \& technology and foreign trade activities peaked in recent years. Changes in the work environment stemming from globalization have brought about some practical concerns regarding the management of multicultural teams (Thomas, 1999). According to Jarvenpaa and Leidner (1999), multicultural teams can be formed in three ways. Firstly, a multicultural team is the team that consists of members from diverse cultural backgrounds including expats or ethnic minorities working together in the same country. Secondly, it is a team that possesses members who are dispersed in many countries but occasionally meet up in person. And thirdly, virtual teams that possess members from various countries, working together via electronic devices and medias and not meeting in person. It is important to mention right here that we are going to focuse on the first type of teams in this study.

Multicultural teams are defined as "task-oriented groups comprising people of different cultural backgrounds" by Marquardt and Horvath (2001). In addition, in their study, Halverson and Tirmizi (2008) define multicultural teams as

"a collection of individuals with different cultural backgrounds, who are interdependent in their tasks, who share responsibility for outcomes, who see themselves and are seen by others as an intact social entity embedded in one or more larger social systems, and who manage their relationships across organizational boundaries and beyond".

\subsection{Pros and Cons of Having Multicultural Teams}

In the literature, there are several studies accentuating the advantages and disadvantages of having multicultural teams. Brannen and Salk (2000) suggest that cultural diversity doesn't impact team performance in a negative way. In other words, they claim that what creates a conflict in a team is not the differences of team members. A review completed by William and O'Reilly (1998) conclude that diversity has no predictable effect on team performance. In addition, cultural diversity in an organization is asserted to serve as an asset instead of liability (Williams and O'Reilly, 1998; Stahl et al., 2010). Some studies show that heterogenous teams outperform homogenous teams. It is suggested that multiple perspectives, varied experiences, different problem-solving and decision-making styles and smart ideas prevail in multicultural teams (Adler, 2002).

Due to diversity, multicultural teams are more prone to face difficulties including language barriers, ineffective communication and differences in communication styles (Adler, 2002). While heterogeneity in group increases, cultural differences are considered to make communication more difficult in group and undermine the development of group norms. (Bettenhausen and Murnighan, 1985; Jehn et al., 1999; Ely \& Thomas, 2001; Behfar et al., 2006). Diversity is likely to create a propensity toward conflict and subconsciously-held cultural differences and sources of conflict are tough to detect and annihilate (Kirchmeyer and Cohen, 1992). According to De Dreu \& Weingart (2003), conflicts in multicultural teams are negatively related to team performance. As it can be understood, there are certain advantages and disadvantages of having multicultural teams or diversity in the organization. The attitude of an organization towards diversity may be considered to be influenced by the way a manager tackles with them and perceives the pros and cons of these differences. While some managers underestimate cultural diversity, and try to remove it in the organization, some might deem these differences as an advantage enhancing company performance and try to support cultural diversity in the organization. Therefore, view of the organization on this matter is likely to be impressed by the managers working for the organization.

\section{DATA AND METHODOLOGY}

For this study, data was collected from primary and secondary sources. Secondary sources consisted of books, articles and magazines which were used to constitute the theoretical parts of the study. Main data for the study was collected through in-depth interviews directed to executive managers of MNCs operating in Turkey. The objective of the interview was to explore the issues/problems related to multicultural team management and the solutions recommended by executive managers. The questions that generated our data consisted of open-ended questions. The statements of managers were analyzed by content analysis.

As mentioned, study focused on executive managers working for MNCs operating in Turkey. However, it was not an easy task to have access to a list indicating the name of MNCs in Turkey. Therefore, it was made use of the list published by Fortune Magazine that revealed the biggest 500 companies of 2017 in Turkey. Purposive sampling method, which is one of the most commonly used and the fittest sampling techniques in qualitative researches (Marshall, 1996; Palys, 2008: 697; Sekaran and Bougie, 2016: 248), was employed. Based 
upon the objective of the study, purposive sampling method is classified into certain kinds. Taken this in consideration, appropriate sampling method for this study was cosidered to be criterion sampling (Palys, 2008: 697). In this sense, companies that constituted the sample of the study were selected from the list based upon their country-origins. It was aimed to get an appointment from the first 50 foreign corporations in the list and ultimately 14 in-depth interviews were conducted by appointment.

First part of the questionnaire concerns about the personal background of the participators. Demographic or general information, which executive managers were requested to answer, was determined as gender, age, nationality, educational background and working experience (years). Lastly, main questions of the study were "As compared to homogeneous teams, what are the challenges confronted while managing multicultural teams?" and "How do you address or manage these challenges?".

\section{FINDINGS}

The sample of the study consisted of 14 individuals with multicultural team experience. While 64 percent of the participants were male, the rest, namely 36 percent, were female participants. Ages of the participants ranged from 26 to 39 , with an average of about 32 years. 43 percent of the participants were from Turkey while the remaining 57 percent consisted of people from Germany (29 percent), Poland ( 7 percent), Korea (7 percent), China (7 percent) and the USA (7 percent). In addition, 43 percent (six out of 14) of participants in the sample had a master's degree while 57 percent (eight out of 14) participants had a bachelor's degree. On the basis of working experience, while the maximum year was 12, the minimum year was 3 with an average of about 7 years.

As a result of the content analysis obtained from primary data, the challenges that managers confront, and the solutions they have come up with are identified as follows. The challenges grouped under three headings including ineffective communication and misunderstandings, different working styles and expectations, and intolerance and lack of knowledge related to diversity. On the other hand, the solutions that managers come up with are also categorized under three headings. They include embracing diversity and encouraging team members to acknowledge it, becoming approachable and eager to learn more, and communicating in a simple and straightforward way. In the following sections, both the problems and advices related to multicultural team management will be detailed and discussed.

\subsection{Challenges}

Ineffective Communication and Misunderstandings: Since they come from diverse cultural settings, it is very likely for team members to have different communication styles. Different communication styles of group members are likely to create controversy about certain issues including the deadlines of the assignments and due dates of the projects. So, one of the problems that managers face within this context is the controversy among group members about the deadline of a task or a project. For instance, when it is said that the task must be submitted at the end of the day, some people are likely to regard it as the end of the shift whereas the interpretation of 'at the end of the day' is likely for others to be the beginning of a new day or midnight. Therefore, it can be said that communication is harder, and misunderstandings happen very easily. Besides, circumstances of how and what you say are important since some group members expect to be addressed directly whereas others indirectly. In other words, some nations value directness whereas others reckon this being rude. It takes more time to explain assignments in heterogeneous teams. In homogenous teams, members are more willing to share their ideas and debates are less superficial. For instance, if more than two members of the team come from different countries, the language in use is always English. Therefore, communication is harder and requires efforts to avoid misunderstandings. In this context, not sharing the same language is likely to create misunderstandings and disagreements among team members due to some reasons including inadequate language skills to clearly and assertively express what they want or need even though they exactly know what is required to do. Inadequate language skills of some team members prevent them from expressing themselves clearly and assertively. This kind of challenge is likely to occur during brainstorming sessions or meetings. And because of misunderstandings, multicultural teams face a lot more problems than teams that are homogenous. These problems are likely to cause such issues including mistrust, misunderstanding of the tasks, schedules and so on.

71 percent (ten out of 14 ) of the participants claim that the most significant challenge they face is ineffective communication and misunderstandings.

Different working styles and expectations: The way team members require directions to achieve assignments varies based on cultures. For instance, while some of the members expect to have autonomy on a task, others are likely to expect explicit directions from the team manager to set to work. Attitudes, values and the way of building relationship differ from culture to culture. The working styles and ethics among multicultural team members are very likely to differ. While some cultures more emphasize on private time and work-life balance, it might be more acceptable and will not be perceived as exploitation to ask employees to work more than eight hours a day in some cultures. In addition, perception of responsibility and authority will be different. Besides, the way people are motivated is likely to be different based upon their culture. Some people are likely to get motivated with a suitable compensation system in a stable environment. On the other hand, for some people, a reasonable salary and a working environment in which relationship matters would be more motivational. Nevertheless, Chinese, Korean and Indian people will be happier to follow instructions from their superiors compared to those who are used to work independently and do not request instructions or guidance.

Approximately 36 percent (five out of 14) of the participants accentuate that the second most important problem in the multicultural teams is different working styles and expectations of team members stemming from diverse cultural background.

Intolerance and lack of knowledge related to diversity: In the words of a manager, when you approach someone in your team, the very first thing you should keep in mind is that you must respect for diversity. There might be people who come from different countries, speak different languages, believe in different Gods or have different skin tones. Do not use these differences to crack a joke or start a conversation. Team members, if they are not trained about diversity, will be more irritated and less tolerant about the differences. 
Intolerance and lack of awareness of team members and managers about these issues lead to frictions and conflicts in the team. Then, team members are likely to underperform under these circumstances unless the manager knows how to tackle with these issues.

About 28 percent (four out of 14 ) of the participants regard that intolerance and lack of knowledge related to diversity is a problem that must be addressed.

\subsection{Solution Offers}

Embrace diversity while encouraging group members to acknowledge it: A work environment in which managers embrace diversity while encouraging group members to acknowledge it is quite significant. Group members need to be trained about cultural diversity and working in a multicultural team. They should know that they must embrace this diversity and respect the differences. So, the manager should be aware of and alert to conflicts among team members in the group and provide knowledge and encourage members to learn about cultural differences. Openness to new things and unfamiliar cultures as well as high level of tolerance is important. Always reminding yourself that different attitudes are coming from another culture which might mean different than in your own culture. Ethnocentrism will not work in this context. Also, learning the way of building relations with each culture is important if one wants to succeed in a multicultural team. Change in a team starts with the manager. Listening to and respecting the opinions from other members, accepting differences and having appropriate reactions toward tricky situations are good points for managers as role models. Being aware of cultural differences in the team, listening and understanding the problems of team members and providing support and encouragement mean a lot.

About 86 percent (12 out of 14) of the participants suggest embracing diversity and encouraging group members to acknowledge it.

Be approachable and eager to learn more: A manager should be accessible and assure that team members can talk about their problems whenever they need even after team meetings. It is important because some team members are likely not to bring some issues up in group meetings and they prefer talking about these issues privately. Being proactive is important at this point that letting members feel free to mention their concerns privately. Managers must be approachable, considerate, consultative and tolerant in this respect. Sense of humor is also an important skill for managers to have. It is vital to be able to build a relationship and better grasp the problems in the team.

Almost 36 percent (five out of 14) of the participants highlight the importance of being approachable and eager to learn about as to resolving the problems in multicultural teams.

Communicate in a simple and straightforward way: Managers need to be simple when it comes to communication. When it is simple and straightforward, it enables parties to build a sound relation and understanding. This is important because team members are likely to interpret the transmitted message in a wrong way if the message is not delivered straightforwardly. Therefore, communicating in a way that makes the expectations and problems clear and obvious is a milestone for an effective communication to avoid misapprehensions.

Nearly 29 percent (four out of 14) of the participants recommend that communicating in a simple and straightforward way avoids the debates and conflicts in the team.

\section{CONCLUSION}

Results of the study is expected to provide managers with a guideline about how to effectively manage multicultural teams and solve the conflicts arising within this context. Effective communication is harder and a big issue in multicultural teams, because misunderstandings may happen easily. Working style and expectations differ a bit among the cultures. Managers must be aware of these differences to better understand and intervene when it is required. Besides, intolerance and lack of awareness of team members and managers about diversity lead to frictions and conflicts in the team. Then, team members are likely to underperform under these circumstances unless the manager knows how to handle them. Because the manager is the only one who is in charge of them all.

A work environment in which managers embrace diversity while encouraging group members to acknowledge it is quite significant. Multicultural teams are more prone to confront difficulties. A manager must be approachable, considerate, consultative and tolerant and reassure that members can talk any problem whenever they need. Last but not least, in order to avoid any conflict and misunderstandings, a manager is expected to be simple and straightforward while communicating. There is no absolute accuracy when it comes to managing multicultural teams. A manager will be what his or her team is. If the team is a poor performer, the manager of the team will be seen as a poor performer or vice versa. Successful managers are expected to possess the competency to adapt different management styles. They are also expected to be eager to learn more and flexible enough to switch from one management style to another. This is significant to benefit multiple perspectives, different experiences, different problem-solving and decision-making styles and new ideas which prevail in multicultural teams.

\section{REFERENCES}

Adler, N. J. (2002). International dimensions of organizational behavior, (4th ed.). Cincinnati, OH: Southwestern.

Aritz, J., Walker, R. C. (2014). Leadership styles in multicultural groups: Americans and East Asians working together. International Journal of Business Communication, vol. 51, no. 1, p. 72-92.

Behfar, K., Kern, M., Brett, J. (2006). Managing challenges in multicultural teams. In National culture and groups. Emerald Group Publishing Limited, p. 233-262.

Bettenhausen, K., Murnighan, J. K. (1985). The emergence of norms in competitive decision-making groups. Administrative Science Quarterly, p. 350-372. 
Brett, J. M. (2007). Negotiating globally: how to negotiate deals, resolve disputes, and make decisions across cultural boundaries. John Wiley \& Sons, San Francisco: Jossey-Bass.

De Dreu, C. K. W., Weingart, L. R. (2003). Task versus relationship conflict, team performance, and team member satisfaction: a metaanalysis. Journal of Applied Psychology, vol. 88, no. 4, p. 741-749.

Dunning, J. H. (2002). Global capitalism, FDI and competitiveness (vol. 2). Edward Elgar Publishing.

Ely, R. J., Thomas, D. A. (2001). Cultural diversity at work: the effects of diversity perspectives on work group processes and outcomes. Administrative Science Quarterly, vol. 46, no. 2, p. 229-273.

Halverson, C. B., Tirmizi, S. A. (Eds.). (2008). Effective multicultural teams: theory and practice (vol. 3). Springer Science \& Business Media.

Helvacıoğlu, N., Özutku, H. (2010). Kültürel farklılıkların yönetiminde insan kaynakları stratejilerinin rolü: IKEA Örneği. Yönetim Bilimleri Dergisi, vol. 8, no. 1.

Hofstede, G. (1991). Organizations and cultures: software of the mind. McGrawHill, New York.

Jarvenpaa, S. L., Leidner, D. E. (1999). Communication and trust in global virtual teams. Organizational Science, vol. 10, no. 6, p. 791-816.

Jehn, K. A., Northcraft, G. B., Neale, M. A. (1999). Why differences make a difference: a field study of diversity, conflict and performance in workgroups. Administrative Science Quarterly, vol. 44, no. 4, p. 741-763.

Kirchmeyer, C., Cohen, A. (1992). Multicultural groups: their performance and reactions with constructive conflict. Group \& Organization Management, vol. 17, no. 2, p. 153-170.

Lisak, A., Erez, M. (2015). Leadership emergence in multicultural teams: the power of global characteristics. Journal of World Business, vol. 50 , no. 1, p. 3-14.

Mäkilouko, M. (2004). Coping with multicultural projects: the leadership styles of Finnish project managers. International Journal of Project Management, vol. 22, no. 5, p. 387-396.

Marquardt, M., Horvath, L. (2001). Global teams: how top multinationals span boundaries and cultures with high-speed teamwork. Palo Alto, CA: Davies-Black Publishing.

Marshall, M. N. (1996). Sampling for qualitative research. Family Practice, vol. 13, no. 6, p. 522-526.

Matveev, A., Milter, R. (2004). The value of intercultural competence for performance of multicultural teams. Team Performance Management, vol. 10 no. 5/6, p. 104-111.

Molinsky, A. (2013). Global dexterity: how to adapt your behavior across cultures without losing yourself in the process. Harvard Business Review Press.

Palys, T. (2008). Purposive sampling. In L. M. Given (Ed.) The Sage Encyclopedia of Qualitative Research Methods. (vol.2). Sage: Los Angeles, p. 697-698.

Ramthun, A. J., Matkin, G. S. (2012). Multicultural shared leadership: a conceptual model of shared leadership in culturally diverse teams. Journal of Leadership \& Organizational Studies, vol. 19, no. 3, p. 303-314.

Sekaran, U., Bougie, R. (2017). Research methods for business: a skill building approach. John Wiley \& Sons.

Stahl, G. K., Maznevski, M., Voigt, A., Jonsen, K. (2010). Unraveling the effects of cultural diversity in teams: a meta-analysis of research on multicultural work groups. Journal of International Business Studies, vol. 41, p. 690-709.

Thomas, D. C. (1999). Cultural diversity and work group effectiveness: an experimental study. Journal of Cross-Cultural Psychology, vol. 30 no. 2, p. 242-263.

Williams, K. Y., O'Reilly III, C. A. (1998). Demography and diversity in organizations: a review of 40 years of research. Research in Organizational Behavior, vol. 20, p. 77-140. 